\title{
ÍNDICE DE AUTORES
}

Volume 8 - 2015

A

AKEL, G. M.

ALCÂNTARA, L. C. S.

ALVES, P. A.

ANJOS, S. J. G. dos

ARAGÃO, I. R.

ARAÚJO, F. S. G.

B

BARBOSA, A. S.

BARRETO, L. M. T. da S.

C

CENSON, D.

D

DAMASIO, J. dos S.

DANTAS, L. M. R.

DEMCZUK, P. G.

DOMARESKI-RUIZ, T. C.

F

FALCÃO, R. P. de Q.

FARIAS, K. S. da S.

FEGER, J. E.

FEUSER, S.

FIGUEIREDO, S. L.

G

GÂNDARA, J. M. G.

H

HOFFMANN, M. G.

K

KLEIN, A. L.

KORSTANJE, M. E.

L

LAPA, T. A.

LIMA, L. M. G.

LOPES, A. S.

LOPES, M. M.

\section{M}

15 MASCARENHAS, R. G. T.

419

511

38

321

99

401 MOLA, J. L.

38

O

OHE, Y.

58

145

38 OMAR, O. A. M. S.

301

555

$\mathbf{P}$

PACHECO, I. B.

234

PEREIRA, P. V. V. 511

PIRES, P. dos S.

276

301

276

234

15

$\mathbf{R}$

RAMÓN CARDONA, J. 255

ROCHA, S. B. 601

RODRIGUES, M. S. 555

$601 \quad$ S

575 SAMPAIO, C. A. C. 342

532 SANTOS, M. R. 446

342 SANTOS, R. A. 446

575 SATO, G. S. 58

SHIMOURA, S. $\quad 58$

SILVA, E. V. da 321

15 SILVA, E. G. da 38

SILVA, K. de O. da 75

SILVA FILHO, J. T. da 401

301 SILVEIRA, E. J. da 180

SONAGLIO, K. E. $\quad 360$

SOUZA, J. T. de 419

467 SOUZA, L. H. 124

162 SOUZA, M. de 467

$\mathbf{T}$

124 TEIXEIRA, D. 145

218 TOMAZZONI, E. L. 489 